NBER WORKING PAPER SERIES

\title{
CONSUMPTION PREFERENCES, ASSET DEMANDS, AND DISTRIBUTION EFFECTS IN \\ INTERNATIONAL FINANCIAL MARKETS
}

\author{
Paul Krugman \\ Working Paper No. 651 \\ NATIONAL BUREAU OF ECONOMIC RESEARCH \\ 1050 Massachusetts Avenue \\ Cambridge MA 02138 \\ March 1981
}

The research reported here is part of the NBER's research program in International Studies. Any opinions expressed are those of the author and not those of the National Bureau of Economic Research. 
In recent years the conventional wisdom about exchange rates has shifted from an exclusive emphasis on current and expected future money supplies to a new view which assigns an 1mportant role to the current account. In spite of the popularity of this new view, however, there has been little agreement on the actual channel through which the current account affects the exchange rate. There seem to be three distinct positions. One position, exemplified by Mussa (1980) and given some empirical support by the work of Freedman (1979), is that the current account matters only because it is an indicator of long-run shifts in the purchasing power parity relationship. A second position, developed theoretically by Dornbusch and Fischer (1980) and given some empirical support by recent work by Frankel (1980), is that the current account matters because wealth affects the demand for money. Finally there is the portfolio balance approach developed by Branson (1977) and Kouri (1976a). In this view, the redistribution of world wealth which current account imbalances produce alters the demand for bonds denominated in different currencies, producing shifts in interest differentials which in turn alter relat ive money demands.

This paper is an attempt to examine some of the microeconomic foundations of this last - iew of the link between current accounts and exchange ratajSeveral authors, especially Kouri and de Macedo (1978), but also more recently Dombusch (1980), have sought to justify the portfolio approach in terms of finance theory, deriving asset demands from a mean-variance framework and arguing that differences in the portfolios of different countries explain why changes in the world distribution of wealth affect exchange rates. What 
I will do in this paper is to argue that, even under seemingly favorable assumptions, these distribution effects may run the wrong way; that if they run the right way, they w11l be very weak; and that the incentives for international portfolio diversification are in any case small, and can be swamped by quite modest transaction costs or other costs to diversification.

This paper is in four sections. Section 1 briefly reviews the argument about how an effect of current accounts on exchange rates can be justified in a finance theory framework, then shows by a numerical example how the effect can run in the wrong direction. Section 2 sets out a formal model in which the condition for distribution effects running the right way can be explicitly derived. Section 3 then develops a continuous-time model in which an expliclt algebraic treatment of the distribution effect on the forward premium can be conducted, and uses some semi-realistic numbers to show the effect's unimportance. Finally, Section 4 considers the gains to diversification, and presents an argument that transaction costs may be as important or more important than mean-varlance considerations in determining International portfollos.

\section{Wealth Distribution and the Forward Premium.}

As Kouri and de Macedo (1978) have pointed out, the essence of the portfollo balance explanation of the current account's role in exchange rates lies In what they call the "wealth transfer effe:". Suppose that Americans ni ${ }^{-1} \mathrm{~d}$ a higher proportion of their wealth in dollar denominated assets than Germans do. Then a redistribution of wealth from America to Germany, occurring over time tinrough current account $1 \mathrm{mbalances,} \mathrm{will} \mathrm{reduce} \mathrm{the} \mathrm{demand} \mathrm{for} \mathrm{dollar}$ denominated assets and Increase the demand for mark denominated assets, requiring either a rise in the U.S.-German interest differential or a depreciation of the dollar. The role of the current account in exchange rate determination. 
arises from the assumed tendency of residents of each country to hold a larger proportion of their wealth in domestic-currency-denominated assets than foreigners do. (This is a point which is somewhat obscured in "smal1 country" . mode1s, such as those of Branson (1977), Kouri (1976a), and Dornbusch and Fischer (1980), in which it is assumed that the home country holds foreign assets but foreigners do not hold domestic assets. This of course implies that home country residents do hold a larger share of their wealth in domestic-currency denominated assets; and it is this, 'rather than the small-country aspect of the story, which really does the work of moving the exchange rate).

Where finance theory comes into this story is in explaining why residents of each country should have a "local habitat" in domestic bonds. Essentially, it is argued that Americans hold American assets because they buy American goods. That is, because the consumption basket of each country is weighted toward domestically produced goods whose prices are set in domestic currency, risk averse investors will tend to choose a portfolio with a disproportjonate share of assets denominated in domestic currency.

We can clarify the point by considering a world of two countries, America and Britain, where the only assets are nominal bonds denominated in dollars and pounds. Suppose that prices of American and British goods are predictable in terms of dollars and pounds respectively, so that the only uncertainty is about exchange rate changes. Then an individual who consumes only American goods will be able to avoid all risk by holding only dollar bonds, and will hold pound bonds only if they offer a higher expected real return. Similarly, an individual who consumes on $1 \mathrm{y}$ British goods will hold only pound bonds unless offered a higher expected real return on dollar bonds. If we can take it as given that Americans will spend a higher proportion of their. income on American goods than Britains will, this seems to give a simple justification 
for the assunption that domestic residents have a local habitat in domestic currency bonds. The point can be further emphasized if ore goes to a mean-varlance framework, as Kouri and de Macedo (1978), de Macedo (1980), and Dornbusch (1980) do. In such a framework the optimal portfolio consists of a "safe" asset plus a speculative portfolio which depends on expected returns -and the safe asset consists of dollar bonds for a dollar consumer, pound bonds for a pound consumer.

Unfortunately, the case for a wealth transfer effect of the right sign is not as clear-cut as this argument makes it seem. The reason is that expected real returns depend on the consumption basket -- and they do so in such a way as to encourage holding of bonds denominated in foreign currency.

Conslder the example in Table I. For simplicity we consider a situation in which interest rates are zero on both types of bonds. At time $t=0$, one dollar is worth 50p; at time $t=1$, a dollar will with equal probability be worth 1 pound and 30p. Thus the expected number of dollars per pound is $21 / 6$, whlle the expected number of pounds per dollar is .65 .

Table I

$$
\begin{array}{rlrlrl}
t=0: & S & =2 & & \text { or } \quad 1 / S=.5 \\
t=0: & S & =31 / 3 & & \text { or } & 1 / S=.3 \text { with probability } 1 / 2 \\
S & =1 & & \text { with probability } 1 / 2 \\
\mathrm{E}[\mathrm{S}] & =21 / 6 & & \mathrm{E}[1 / \mathrm{S}]=.65
\end{array}
$$

What would an investor do in this situation? It depends on two things: hls consumption tastes, and his degree of risk aversion. One extreme case would be that of completely risk-averse investors. These investors will hold dollar bonds if they consume American goods, pound bonds if they consume-British goods. If Investors are risk neutral, however, this result 
be reversed. Pound bonds have a positive, expected return in terms of dollars, while dollar bonds have a positive expected return in terms of pounds. Thus in this case we will have cross-holding,the reverse of the 1ccal habitat story.

This paradoxical possibility results from Jensen's inequality. There is a smal1 literature on the role of Jensen's inequality in international finance (see Siege1 (1972), Roper (1975), and McCulloch (1975). the upshot of which was that the discrepancy caused by this effect was too small to have any practical importance. One might expect that this would imply that even slight risk aversion would be enough to establish the preferred habitat result. However, this is not the case. Consider a Bernoulli investor, $1 . e .$, one whose utility is linear in the $\log$ of expected wealth. Such an investor would not ordinarily be considered to have an unreasonably low degree of risk aversion. Yet the Bernoulli case is not enough to estab1ish a preferred habitat result. Let $\mathrm{W}$ be wealth in dolla'rs, and $\mathrm{S}$ the dollar-pound exchange rate. Then a Bernoulli investor who consumes American goods will maximize $\mathrm{E}[\ln \mathrm{W}]$, while an investor who consumes British goods will $\operatorname{maximize} E[\ln W / S]=-E[\ln S]+E[\ln W]$. Since $E[\ln S]$ is unaffected by the choice of portfolio, the two investors will hold the same portfolio. (In the example in Table I they will hold 43 percent dollars, 57 percent pounds). This suggests investors w111 have a local hab1tat in bonds only if they are sufficiently risk averse, and that the degree of risk aversion required is not trivial. We will see below that what is in fact required -- as che Bernoulli example may have suggested -- is relative risk aversion greater than one. Furthermore, the example suggests that the role of risk aversion in International portfolio decisions is comparable in magnitude to that of Jensen's inequality -- an effect which has generally been dismissed as trivial. If this is the case, presumably the importance of risk aversion is also minor. Our calculations later will support this view. 


\section{A Formal Mode1.}

The basic idea of the finance theory view of distribution effects on exchange rates is that investors have a "local habitat" biased toward assets denominated in domestic currency because they spend a relatively higher proportion of their income on domestic goods. This presunes, of course, that the purchasing power of domestic currency over domestic goods is more predictable than the purchasing power of foreign currency over domestic goods; i.e., that inflation rates are more predictable than exchange rate changes. This is a reasonable presumption: inflation rates are both much less variable than exchange rate changes and much more serially correlated (see Mussa (1980)). In this section I will carry out a formal analysis which takes this presumption to its logical extreme: price levels will be assumed to be wholly predictable, so that the only source of uncertainty is the exchange rate.

We make the following assumptions:

(1) Investors take their initial wealth, invest it for one period, then use all of their wealth to buy consumption goods.

(ii) There are two countries, America and Britain, each producing a single consumption good.

(iii) There are two assets, bonds denominated in dollars and bonds denominated in pounds.

(iv) Ali inv stors have the same degree of risk aversion, but they difiin their tastes over goods. American investors have a relative preference for American goods.

We will assume that utility can be written in the form

$$
\mathrm{v}=\frac{1}{\gamma}\left[\mathrm{c}_{\mathrm{A}}^{1-\beta} \mathrm{C}_{\mathrm{B}}^{\beta_{j}}{ }^{\gamma}\right.
$$


where $C_{A}, C_{B}$ are consumption of American and Brïtish goods respectively. This is a constant relative risk aversion utility function, with $1-\gamma=R$ the coefficient of relative risk aversion. $R$ will be assumed the same for all individuals. However, $B$, which measures the relative demand for British goods, will be greater for Britons than Americans.

At the beginning of the perfod, investors will allocate their wealth between dollar bonds and pound bonds. They will be bound by the budget constraint

$$
I_{A}+\bar{E} I_{B}=\bar{W}
$$

where $I_{A}$ and $I_{B}$ are holdings of dollar and pound bonds respectively, $\vec{E}$ is the beginning-of-period exchange rate, and $\bar{W}$ is beginning of period doliar wealth.

At the end of the period, wealth measured in dollars will depend on the initital allocation of investment, interest rates, and the uncertain end of period exchange rate. We can regard the exchange rate as taking on any of a number values $E_{i}$, with the probability of each valte being $p_{i}$. In each such state wealth measured in dollars will be

$$
W_{i}=I_{A}\left(1+i_{A}\right)+E_{i} I_{B}\left(1+i_{B}\right)
$$

where $i_{A}, i_{B}$ are the interest yields on dollar and pound bonds respectively. Investors will maximize utility, subject to the budget constraint

$$
\mathrm{P}_{\mathrm{A}} \mathrm{C}_{\mathrm{A}}+\mathrm{E}_{1} \mathrm{P}_{\mathrm{B}} \mathrm{C}_{\mathrm{B}}=\mathrm{W}_{i}
$$

where $\mathrm{P}_{\mathrm{A}}, \mathrm{P}_{\mathrm{B}}$ are the end-of-period prices of American and British goods respectively, to be known with certainty. It is convenient to write the 
result of this maximization as an indirect utilty function,

$$
\mathrm{U}_{i}=\frac{1}{\gamma} \mathrm{w}_{i}^{\gamma}\left[\mathrm{P}_{\mathrm{a}}^{1-\beta} \mathrm{P}_{\mathrm{B}}^{\beta}\right]^{-\gamma} \mathrm{E}_{i}^{-\beta \gamma}
$$

or by choice of units,

$$
U_{i}=\frac{1}{\gamma} W_{I}{ }^{E_{i}}{ }^{-\beta \gamma}
$$

Now consider the investor's decision problem. Each investor will want to maximize expected utility,

$$
E U=\Sigma p_{i} U_{i}
$$

There is one decision variable, investment in pound bonds $I_{B}$, since $I_{A}=W-\bar{E} \cdot I_{B}$. Thus the first order condition is $\frac{\partial E U}{\partial I_{B}}=0$, where

after some manipulation we can show that

$$
\frac{\partial E U}{\partial I_{B}}=K \quad \Sigma_{p_{i}} w_{i}^{\gamma-1} \rho_{i}^{-\beta \gamma} \quad\left(\rho_{i}-1\right)
$$

where $K$ consists of terms which do not vary with the end of period exchange rate, and we define

$$
\rho_{i}=\frac{E_{i}}{\bar{E}} \cdot \frac{1+i_{B}}{1+i_{A}}
$$

We are now prepared to ask the basic question: will British residents hold a larger proportion of their wealth in pound bonds than American residents? This reduces to the question of the sign of $\partial^{2} \mathrm{EU} / \partial I_{B} \partial B$. If this is positive, an increased taste for British goods will lead to increased investment in pound denominated bonds; conversely, if it is negative, a stronger taste for British goods will lead to reduced investment in pound denominated assets. 
Differentiating (7):

$$
\frac{\partial^{\partial} E U}{\partial I_{B} \partial \beta}=-\gamma K \Sigma p_{i} W_{i}^{\gamma-1} \quad \rho_{i}\left(\rho_{i}-1\right) \ln \rho_{i}
$$

Inspecting (9) term by term, we see that all terms will be negative if $\gamma$ is posttive, positive if $Y$ is negative. Recalling that the coefficient of relative risk aversion $R$ is equal to $1-\gamma$, this gives us the basic result: An increased demand for a country's goods leads to an increased demand for assets denominated in its currency if and only if relative risk aversion is greater than one. If relative risk aversion is less than one, the effect runs the "wrong" way.

\section{Distribution Effects: A Continuous Time Mode1}

- If risk aversion is great enough, the wealth transfer" effect will run in the "right" direction. What we would like, however, is a measure of its importance. It will be useful to develop a model in which we can solve explicitly for the effects of a redistribution of world wealth on the equilibrium interest differential.

Recently Kouri (1976b) de Macedo (1980) and Stulz (1980) have applied the analysis of continuous time portfolio models to international finance. The basic result we need from this analysis is the following: suppose an in'. vestor has a constaint relative rish aversion utility function of the form

$$
\mathrm{U}=\int_{0}^{\mathrm{T}} \frac{1}{\gamma} \tilde{\mathrm{C}}^{\gamma} \mathrm{dt}
$$

where $\tilde{C}$ is real consumption. Suppose further that real returns on the assets available follow Brownian motion. Then at each point in time the 
investor will choose a portfolio which maximizes

$$
V=E(\tilde{d} / \tilde{W})-\frac{1}{2} R \operatorname{var}(\tilde{d W} / \tilde{W})
$$

where $\tilde{\mathrm{W}}$ is real weal.th, $\tilde{\mathrm{dW}} \tilde{\mathrm{W}}$ is its instantaneous rate of change, dind $R=1-\gamma$ is the coefficient of relative risk aversion.

Applying this to the international problem, we simply note that real wealth $\tilde{W}$ may be defined as

$$
\tilde{W}=W E^{-\beta} P_{A}^{\beta-1} P_{B}^{-\beta}
$$

where $W$ is dollar wealth, $E$ the exchange rate, $P_{A}$ and $P_{B}$ the own currency prices of American and British goods, and $B$ the share of British goods in consumption.

As in the last section, we assume that there is no uncertainty about prices. Each price level will be assumea to grow at a constant rate:

$$
\begin{aligned}
& \mathrm{dP}_{A}=\pi_{A} \cdot P_{A} d t \\
& d_{B}=\pi_{B} P_{B} d t
\end{aligned}
$$

The exchange rate will, however, follow Brownian motion:

$$
d E=\delta E d t+E s d z
$$

where $\mathrm{d} z$ is the random element.

Let us also assume that dollar and pound bonds bear fixed nominal rates ${ }_{A}$ and $i_{B}$ respectively. Also, let $\lambda$ be the share of wealth put into pound bonds. Then by Itô's Lemma, we can write the instanstaneous change in $\tilde{\mathrm{W}}$ as

$$
\begin{aligned}
\tilde{\mathrm{dW} / \tilde{W}}= & (1-\lambda) i_{A}+\lambda i_{B} \\
& -(1-\beta) \pi_{A}-\beta \pi_{B} \\
& +(\lambda-\beta) \frac{d E}{E}+\frac{1}{2}\left(\beta^{2}+\beta-2 \beta \lambda\right)\left(\frac{d E}{E}\right)^{2}
\end{aligned}
$$


The "Jensen's inequality" or "Siege1 paradox" effect can be seen in the last term. As long as $\beta>0$, that is, as long as there are some British goods in one's consumption basket the real return on a portfolio depends not only on the rate of change of the exchange rate but on its variance.

Substituting from (14) and taking expectations, we find

$$
\begin{aligned}
E[\tilde{\tilde{W} / \tilde{W}]=} & (1-\lambda) i_{A}+\lambda i_{B} \\
& -(1-\beta) \pi_{A}-\beta \pi_{B} \\
& +(\lambda-\beta) \delta+\frac{1}{2}\left(\beta^{2}+\beta-2 \beta \lambda\right) s^{2}
\end{aligned}
$$

for the expected return on the portfolio; and

$$
\operatorname{var}(\tilde{\mathrm{d}} / \tilde{W})=(\lambda-\beta)^{2} s^{2}
$$

for its variance.

We can now solve for the optimum share of pound-denominated assets.

The first-order condition is $\frac{\partial V}{\partial} \frac{V}{\partial}=i_{B}+\delta-i_{A}-\beta S^{2}-R(\lambda-\beta) s^{2}=0$

$$
\text { or } \lambda=\frac{1}{\mathrm{RS}^{2}}\left[i_{\mathrm{B}}+\delta-i_{\mathrm{A}}+(\mathrm{R}-1) B \mathrm{~S}^{2}\right]
$$

It is immediately apparent that a higher share of British goods in consumption implies a higher share of pound denominated assets in one's portfolio if and only if $R>1$. Further, since $\partial \lambda / \partial \beta=R-1 / R$, this effect will be small unless risk aversion is considerably more than one and will in any case be less than proportionate.

Given the expression of portfolio choice (18), we can now proceed to an analysis of the size of distribution effects on the forward premium (i.e., the interest differential). Let

$$
\begin{aligned}
& D_{A}, D_{B}=\text { supplies of dollar-and pound-denominated bonds } \\
& W_{A} \cdot W_{B}=\text { dollar wealth of Americans and Britons }
\end{aligned}
$$


$\beta_{A}, \beta_{B}=$ share of British goods in the consumption of Americans and Britons

$\lambda_{A}, \lambda_{B}=$ share of pound assets in the portfolios of Americans and Britons

We assume that $\beta_{B}>\beta_{A}$; the question is whether this difference in consumption patterns gives rise to a significant distribution effect in the asset market.

By (18), we have

$$
\begin{aligned}
& \lambda_{A}=\frac{1}{\mathrm{RS}^{2}}\left[1_{B}-1_{A}+\delta+\beta_{A}(R-1) S^{2}\right] \\
& \lambda_{B}=\frac{1}{\mathrm{RS}^{2}}\left[1_{B}-i_{A}+\delta+\beta_{B}(R-1) S^{2}\right]
\end{aligned}
$$

The market clearing condition is

$$
\lambda_{\mathrm{A}} \mathrm{W}_{\mathrm{A}}+\lambda_{\mathrm{B}} \mathrm{W}_{\mathrm{B}}=\mathrm{E} \mathrm{D}_{\mathrm{B}}
$$

We can divide both sides of (20) by total world wealth, $\mathrm{W}_{\mathrm{A}}+\mathrm{W}_{\mathrm{B}}=\mathrm{D}_{\mathrm{A}}+\mathrm{ED}_{\mathrm{B}}$, and rearrange to get an expression for the forward premium as a function of the share of pound assets in world assets supplies and the British share in world wealth:

$$
\begin{aligned}
i_{B}-i_{A}=-\delta & -\beta_{A}(R-1) s^{2}+R s^{2} \frac{E D_{B}}{D_{A}+E D_{B}} \\
& +(R-1) s^{2} \frac{W_{B}}{W_{A}+W_{B}}\left(\beta_{A}-\beta_{B}\right)
\end{aligned}
$$

What (21) says is that: (i) an increase in the relative supply of pounds will lower the forward premium on pounds; (ii) an.increase in the British share of world wealth will raise the forward premium on pounds if relative risk aversion is greater than one and Britons have a relatively stronger taste for British goods.

For plausible parameter values, however, this last effect is very weak. Consider the effect of redistributing one percent of world wealth from 
America to Britain -- a very large quantity compared with the wealth redistribution actually involved in recent current account imbalances. Suppose we also make the most extrame assumption about consumption baskets, namely that $\beta_{A}=0, \beta_{B}=1$. Then the change in the forward premium is $.01 \mathrm{RS}^{2}$. A widely accepted "reasonable" value for $R$ is 2 .

Table 2: Variability of Exchange Rates

Mean squared annual change in log of exchange rate, June 1973-June 1980

$\begin{array}{lll}\text { Dollar/mark } & . & .0114 \\ \text { Dollar/yen } & .0186 \\ \text { Dollar/pound } & .0191\end{array}$

l'able 2 gives some representative numbers on exchaige rate variability. Using these numbers, we find that redistributing one percent of world wealth would lead to a change in the forward premium of less than .02 percentage points.

Given sufficiently strong risk aversion, then, it is possible to explain both imperfect substitutability of bonds and distribution effects on interest rates. But given realistic numbers, these effects will be very small. If distribution effects in international financial markets do play an econonically significant role, they must arise from sources other than risk aversion.

\section{Will Investors Diversify Internationa1ly?}

In the last section we saw that for reasonable estimates of relative risk aversion and actual exchange volatility the economic importance of international. portfolio diversification seems doubtfu1. A natural question is whether investors themselves will bother to diversify. Realistically, there will be some costs to international diversification of one's portfolio. Will the advantages be 
large enough to outweigh these?

To ask"this question we' need to formulate the costs of diversification. It seems most natural to suppose that there is a fixed cost to diversification. However, in the continuous time formulation this will not be tractabie. We can easily handle the cost, however, if we model it as a fixed cost per unit time; this can be viewed as an approximation to a situation where there is a simple fixed cost. The cost per unit time will simply be the fixed cost divided by the maturity of the security.

Our revised model of portfolio choice can be written as follows. Let $f$ be a fixed cost per unit time which an investor must incur if he chooses to hold any foreign currency bonds. Thus the change in an internationally diversified investor's wealth will be

$$
\begin{aligned}
\tilde{\mathrm{dW} / \tilde{\mathrm{W}}=} & -\tilde{f} / \tilde{\mathrm{W}} \\
& +(1-\lambda) i_{A}+\lambda_{B} \\
& -(1-\beta) \pi_{A}-\beta \pi B \\
& +(\lambda-\beta) d E / E \\
& +\frac{1}{2}\left(\beta^{2}+\beta-2 \beta \lambda\right)(\mathrm{dE} / E)^{2}
\end{aligned}
$$

An investor who holds only domestic currency bonds, however, need not incur the fixed cost. Thus an American holding only do1lar bonds will have

$$
\begin{aligned}
\tilde{\mathrm{dW} / \tilde{W}=} & i_{A}-(1-\beta) \pi_{A}-\beta \pi_{B} \\
& -\beta \mathrm{dE} / \mathrm{E} \\
& +\frac{1}{2}\left(\beta^{2}+\beta\right)(\mathrm{dE} / \mathrm{E})^{2}
\end{aligned}
$$

Under what conditions will investing only in domestic currency be preferred? Let

$$
\begin{aligned}
& v_{0}=\text { utility with optimal diversification } \\
& v_{N}=\text { utility without diversification }
\end{aligned}
$$


Then we can show that

$$
\begin{aligned}
V_{D}-V_{N}= & -f / \tilde{W} \\
& +\frac{1}{2 R_{S}^{2}}\left[i_{B}+\delta-i_{A}+(R-1) B S^{2}\right]^{2}
\end{aligned}
$$

If $\mathrm{f} / \tilde{\mathrm{W}}$ is large enough compared with second term, investors will not diversify.

Consider the following example. Suppose

$$
E[d E / E]+i_{B}-i_{A}=E[d(1 / E) /(1 / E)]+i_{A}-i_{B} ; \text { i.e., from the }
$$

point of view of nominal returns in the other currency neither currency appears more attractive. This can be shown to imply

$$
\delta=i_{A}-i_{B}+s^{2} / 2 \text {. This is as close as we can get to a situation }
$$
of pure diversification, since setting $\delta=i_{A}{ }^{-i}{ }_{B}$ would actually mean providing a differential in real returns.

In this case, the interest rates drop out and the critical level of fixed costs depends only on $R, \beta$, and $s^{2}$. Suppose $R=2, s^{2}=.02$, and $\beta=.2$. Then $\dot{V}_{D}-V_{N}$ will be $.00245-f / \tilde{w}$.

What this means is that a cost equal to .245 percent of wealth at an annual rate will deter diversification. For short maturities this can be a quite small number. For three-month securities, for instance, an investor with $\$ 10,000$ will be deterred by costs of $\$ 6.13$; an investor with $\$ 100,000$ by costs' of $\$ 61.25$.

These calculations suggest that for many investors the costs of international diversification will be enough to block such diversification.

In practice, international portfolio diversification is not sornething that ordinary individuals do. Instead, it is more typically something that we associate with firms and individuals whose utility depends on the exchange rate in a "leveraged" way -- e.g., importers who must commit themselves to pay for foreign goods in future. This analysis suggests why. And it fur- 
16.

thur suggests that a realistic analysis of international financial markets

must take into account the fact that international investment is not costless. 


\section{$\underline{\text { Referencet; }}$}

Branson, W. (1977): "Asset Markets and Relative Frices in Exchange Rate Determination," Sozialwissenschaftiche Annalen, 1.

Dornbusch, R. and S. Fischer (1980): "Exchange Rates and the Current Account," $\underline{\text { AER }}$ (Dec.)

Frankel, J. (1980): "The Mystery fo the Multiplying Marks: A Modification of the Monetary Model," NBER Working Paper \#"

Freedman, C. (1979): "The Canadian Dollar, 1971-76: An Exploratory Investigation of Short-Run Movements," NBER Working Paper $\$ 380$.

Kouri, P. (1976a): "The Determinants of the Forward Premium," mimeo, Institute for International Economic Studies, Stockholm.

(1976b): "The Exchange Rate and the Balance of Payments in the Short Run and in the Long Run: A Monetary Approach," Scandinavian Journal of Economics, 2 .

and J. de Macedo (1978): "Exchange Rates and the International Adjustment Process," Brookings Papers on Economic Activity: 1.

de Macedo, J. (1980): "Portfolio Diversification Across Currencies," mimeo, Princeton.

McCulloch, J.H. (1975): "Operational Aspects of the Siegel Paradox," QJE (Feb.).

Mussa, M. (1979): "Empirical Regularities in the Behavior of Exchange Rates and Theories of the Foreign Exchange Market," mimeo, Univ. of Chicago.

(1980): "The Role of the Current Account in Exchange Rate Dynamics," mimeo, University of Chicago. 
18.

Roper, D. (1975): "The Role of Expected Value Analysis for Speculative Decisions in the Forward Currency Market;" QJE, (Feb).

Siege1, J. (1972): "Risk, Interest, and Forward Exchange," QJE, May. 